\title{
A practical method for optimised earth electrode designs at transmission towers exposed to lightning
}

\begin{abstract}
A large percentage of transmission line outages in Malaysia are due to lightning activity with backflashover being the main cause. Previous investigations have indicated that tower footing earth resistance is one of the main factors in reducing the occurrence of backflashovers. The present studies review some of the tower earthing design options. From this standard designs are proposed together with a practical method of optimising the design based on soil resistivity measurement data. The process is presented via a procedure which includes the main measurement and design steps. This allows different standard designs to be selected to suit the type of soil structure at the site of the proposed transmission tower. Where measurements indicate a high resistivity layer with underlying low resistivity soil, an electrode design relying more on driven rods is used. Conversely, a design using more horizontal electrode would be selected where the soil structure is of low resistivity above high. Trial installations using the newly designed electrode arrangements have been conducted and preliminary results indicate significant improvements in lightning performance.
\end{abstract}

Keyword: Transmission towers; Lightning; Transmission tower earthing design 